Supporting information

\title{
Docking Flexible Cyclic Peptides with AutoDock CrankPep
}

\author{
Yuqi Zhang ${ }^{1}$, and Michel Sanner ${ }^{1^{*}}$
}

${ }^{1}$ Department of Integrative Structural and Computational Biology, The Scripps Research Institute, La Jolla, California, United States of America

Table S1. Detailed information for the 18 complexes containing peptides cyclized through their backbones. Group I consist of 12 HIV integrase complexes with various cyclic peptide inhibitors. Group II consists of 4 complexes with a SFTI-1 cyclic peptide. Group III contains 2 complexes that do not belong to the former two groups. The apo structures were superimposed to the holo structures using LovoAlign ${ }^{1}$ and the resulting $\mathrm{C}_{\alpha}$ RMSD values are reported for each apo-holo pair.

\begin{tabular}{|c|c|c|c|c|c|c|}
\hline PDB & $\begin{array}{l}\text { Peptide } \\
\text { Chain }\end{array}$ & $\begin{array}{c}\text { Contacting Receptor } \\
\text { Chain }\end{array}$ & $\begin{array}{l}\text { Peptide } \\
\text { Length }\end{array}$ & Group & $\begin{array}{l}\text { apo } \\
\text { PDB }\end{array}$ & RMSD ( $(\AA)$ \\
\hline 3av9 & $\mathrm{Y}$ & A-B & 8 & I & $5 \mathrm{jl} 4$ & 1.72 \\
\hline 3ava & $\mathrm{Y}$ & $A-B$ & 8 & I & $5 \mathrm{jl} 4$ & 1.72 \\
\hline 3avb & $\mathrm{Y}$ & $A-B$ & 8 & I & $5 \mathrm{jl4}$ & 1.71 \\
\hline 3avf & $\mathrm{F}$ & $A-B$ & 8 & I & $5 \mathrm{jl4}$ & 1.80 \\
\hline 3avg & D & $A-B$ & 8 & I & $5 \mathrm{jl4}$ & 1.74 \\
\hline 3avh & E & $A-B$ & 8 & I & $5 \mathrm{jl} 14$ & 1.76 \\
\hline 3avi & D & $A-B$ & 8 & I & $5 \mathrm{jl} 4$ & 1.76 \\
\hline 3avj & D & $A-B$ & 8 & I & $5 \mathrm{jl4}$ & 1.76 \\
\hline 3avk & D & $A-B$ & 8 & I & $5 \mathrm{jl} 14$ & 1.76 \\
\hline 3avm & D & $A-B$ & 8 & I & $5 \mathrm{jl} 14$ & 1.73 \\
\hline 3avn & G & $A-B$ & 8 & I & $5 \mathrm{jl} 14$ & 1.76 \\
\hline 3wne & $\mathrm{C}$ & A-B & 6 & I & $5 \mathrm{jl4}$ & 2.66 \\
\hline 1sfi & I & A & 14 & II & 1tld & 0.24 \\
\hline 3p8f & I & A & 14 & II & 4is5 & 0.32 \\
\hline 4k1e & B & A & 14 & II & $4 \mathrm{kga}$ & 0.59 \\
\hline 4kel & B & A & 14 & II & $4 \mathrm{kga}$ & 0.61 \\
\hline 3zgc & $\mathrm{C}$ & A & 7 & III & 1u6d & 0.40 \\
\hline
\end{tabular}



$5 \times n 3$
A
8
III

Table S2. Detailed information for the 20 complexes containing a peptide with cycles formed by disulfide bonds only. The apo structures were superimposed to the holo structures using LovoAlign ${ }^{1}$ and the resulting $\mathrm{C}_{\alpha}$ RMSD values are reported for each apo-holo pair.

\begin{tabular}{|c|c|c|c|c|c|}
\hline PDB & $\begin{array}{l}\text { Peptide } \\
\text { Chain }\end{array}$ & $\begin{array}{c}\text { Contacting } \\
\text { Receptor Chain }\end{array}$ & $\begin{array}{l}\text { Peptide } \\
\text { Length }\end{array}$ & аро PDB & RMSD $(\AA)$ \\
\hline 3wnf & $\mathrm{C}$ & A-B & 6 & $5 \mathbf{j l} 4$ & 2.55 \\
\hline $40 u 3$ & B & A & 6 & 4fkh & 0.19 \\
\hline $1 \mathrm{smf}$ & I & $\mathrm{E}$ & 9 & 1tld & 0.19 \\
\hline 5grd & $\mathrm{C}$ & A & 10 & & \\
\hline 3p72 & B & A & 11 & $1 \mathrm{~m} 0 \mathrm{z}$ & 1.04 \\
\hline 2ck0 & $\mathrm{P}$ & H-L & 11 & & \\
\hline 5th2 & $\mathrm{E}$ & $A-B$ & 12 & & \\
\hline 1hqq & $\mathrm{F}$ & B-C & 13 & & \\
\hline 5djc & $\mathrm{C}$ & A & 13 & 5djo & 0.44 \\
\hline 4ib5 & $\mathrm{D}$ & A & 13 & $3 q 9 x$ & 0.63 \\
\hline $5 h 5 q$ & B & A & 13 & 2obi & 0.72 \\
\hline 5eoc & $\mathrm{P}$ & H-L & 13 & & \\
\hline $5 w x r$ & $\mathrm{P}$ & $\mathrm{U}$ & 14 & 4dva & 0.24 \\
\hline $4 \mathrm{~m} 1 \mathrm{~d}$ & $\mathrm{P}$ & H-L & 14 & & \\
\hline $5 \mathrm{vb9}$ & $\mathrm{C}$ & A & 15 & & \\
\hline $1 \mathrm{jbu}$ & $\mathrm{X}$ & $\mathrm{H}$ & 15 & 5pag & 2.42 \\
\hline $5 \operatorname{co5}$ & $\mathrm{C}$ & A-B & 16 & & \\
\hline $3 g 5 v$ & $\mathrm{C}$ & A-B & 16 & & \\
\hline $5 \times 100$ & B & A & 19 & $5 \mathrm{mlb}$ & 0.82 \\
\hline 1vpp & $X$ & V-W & 20 & & \\
\hline
\end{tabular}




\section{Treatment for cyclic backbone closure}

When docking a peptide cyclized through its backbone, $A D C P$ starts from the primary sequence and builds a linear extended conformation. The distance-dependent potential shown below is used to cyclize the peptide backbone and induce the correct bond-distance and bond angle. In the equations below, $d C_{\alpha}$ is the distance between the first and last $C_{\alpha}$ atoms and $d C N$ is the distance between the $\mathrm{C}$ and $\mathrm{N}$ atoms forming the peptide bond.

$$
\text { Energy }=\left\{\begin{array}{c}
d C_{\alpha}, \quad d C_{\alpha}>5 \AA \\
\left(d C_{\alpha}-3.819\right)^{2}+(d C N-1.345)^{2}, d C_{\alpha} \leq 5 \AA
\end{array}\right.
$$

The N-C bond is considered formed when the energy of this potential is below $0.06 \mathrm{kcal} / \mathrm{mol}$ at which point the potential is disabled and the crankshaft motion is allowed for peptide segments spanning this bond.

\section{Treatment for disulfide bond}

We use a similar distance-dependent potential to model the disulfide bond formed between two sulfur atoms from cysteine residues. The optimal bond length for the disulfide bond is $2.2 \AA$ with a $90^{\circ}$ dihedral angle. We observed that using a strong potential here hinders the ability to effectively sample the conformational space of the peptide. Moreover, we want these bonds to be able to form and be broken to pair up different cysteine residues during the simulation. For this reason, we used a relatively soft slope in this potential. In the equations below, $d$ is the distance between the two sulfur atoms and $\chi$ is the dihedral for the $\mathrm{C}_{\beta}-\mathrm{S}-\mathrm{S}-\mathrm{C}_{\beta}$ disulfide bond. The energies are in $\mathrm{k}_{\mathrm{B}} \mathrm{T}$ unit ( $0.59 \mathrm{kcal} / \mathrm{mol}$ at room temperature).

$$
\begin{gathered}
\text { Energy }=-50(\text { LinearDecay }(d)-\operatorname{Angular}(\chi, d)) \\
\text { LinearDecay }(d)=\left\{\begin{array}{c}
1, d \leq 2.2 \AA \\
1.0-\frac{(d-2.2)}{50}, 2.2 \AA<d \leq 52.2 \AA \\
0, d>52.2 \AA
\end{array}\right.
\end{gathered}
$$




$$
\operatorname{Angular}(\chi, d)=\left\{\begin{array}{c}
0, d>3.2 \AA \text { or }|\cos (\chi)| \leq 0.35 \\
(|\cos (\chi)|-0.35), d<3.2 \AA \text { and }|\cos (\chi)|>0.35 \\
-0.2, d \leq 3.2 \AA \text { and }|\cos (\chi)| \leq 0.35
\end{array}\right.
$$


Table S3. Median time in minutes for performing one ADCP MC-replica (out of the 300 per docking used in this paper) when docking cyclic peptides. The reported runtimes are median values as the various MC-replicas making up an $A D C P$ docking were performed on a heterogeneous cluster comprising Intel Xeon CPUs dating from 2007 to 2012. The actual wall clock time depends on the number of cores available for running the 300 replicas in parallel.

\begin{tabular}{|c|c|c|}
\hline PDB & Length & Time(min) \\
\hline 3av9 & 6 & 10.6 \\
\hline 3ava & 6 & 11.1 \\
\hline 3avb & 6 & 11.3 \\
\hline 3avf & 6 & 11.7 \\
\hline 3avg & 6 & 11.0 \\
\hline 3avh & 6 & 14.0 \\
\hline 3avi & 6 & 11.7 \\
\hline 3avj & 6 & 11.5 \\
\hline 3avk & 6 & 12.1 \\
\hline 3avm & 6 & 14.2 \\
\hline 3avn & 6 & 11.9 \\
\hline 3wnf & 6 & 6.9 \\
\hline $40 u 3$ & 6 & 5.1 \\
\hline $3 z g c$ & 7 & 6.6 \\
\hline 3wne & 8 & 6.1 \\
\hline $5 \times n 3$ & 8 & 13.1 \\
\hline $1 \mathrm{smf}$ & 9 & 8.6 \\
\hline 5grd & 10 & 7.6 \\
\hline 3p72 & 11 & 19.2 \\
\hline $2 \mathrm{ck0}$ & 11 & 13.5 \\
\hline 6bae & 12 & 27.5 \\
\hline 1hqq & 13 & 21.7 \\
\hline 5djc & 13 & 21.8 \\
\hline 4ib5 & 13 & 22.3 \\
\hline $5 h 5 q$ & 13 & 42.4 \\
\hline $5 \mathrm{eoc}$ & 13 & 24.7 \\
\hline 1sfi & 14 & 27.8 \\
\hline 3p8f & 14 & 28.0 \\
\hline $4 \mathrm{k} 1 \mathrm{e}$ & 14 & 29.3 \\
\hline 4kel & 14 & 30.7 \\
\hline $5 w \times r$ & 14 & 21.4 \\
\hline $4 \mathrm{~m} 1 \mathrm{~d}$ & 14 & 27.8 \\
\hline $5 v b 9$ & 15 & 33.7 \\
\hline 1jbu & 15 & 44.1 \\
\hline $5 c 05$ & 16 & 26.0 \\
\hline
\end{tabular}




\begin{tabular}{ll|l} 
3g5v & $\mathbf{1 6}$ & 38.1 \\
$\mathbf{5 x c o}$ & $\mathbf{1 9}$ & 92.8 \\
$\mathbf{1 v p p}$ & $\mathbf{2 0}$ & 60.8
\end{tabular}

\section{Reference}

(1) Martínez, L.; Andreani, R.; Martínez, J. M. Convergent Algorithms for Protein Structural Alignment. BMC Bioinformatics 2007, 8 (1), 306. https://doi.org/10.1186/1471-2105-8306. 